\title{
ALGUMAS CONSIDERAÇÕES SOBRE A HISTÓRIA E APLICAÇÕES DA ESTATÍSTICA POR MEIO DA FILATELIA
}

\author{
J. C. PENEREIRO ${ }^{1}$, D. H. L. FERREIRA ${ }^{2}$ \\ ${ }^{1}$ Observatório Municipal de Campinas Jean Nicolini - ${ }^{2}$ PUC-Campinas, CEATEC - Faculdade de Matemática \\ lombardo@puc-campinas.edu.br ${ }^{2}$
}

Submetido 21/12/2016 - Aceito 16/02/2018

DOI: $10.15628 /$ holos.2018.3892

\section{RESUMO}

Este trabalho visa divulgar alguns conteúdos da história da estatística, além de várias aplicações dessa ciência, por meio de imagens contidas em selos postais emitidos por vários países entre 1843 e 2014. Procura-se mostrar que é possível divulgar e ensinar estatística por meio da filatelia, destacando ser este material uma poderosa ferramenta adicional no ensino e aprendizagem, além de um elemento de divulgação científica que possibilita sensibilizar a sociedade sobre a importância dessa ciência em diferentes áreas do conhecimento. No trabalho são apresentadas descrições de alguns selos do levantamento realizado, além de uma proposta do uso desse rico material no ensino da estatística, podendo ser aplicado em disciplinas correlatas.

PALAVRAS-CHAVE: Aplicações em estatística, História da estatística, Ensino da estatística, Filatelia.

\section{SOME CONSIDERATIONS ABOUT THE HISTORY AND APPLICATIONS OF STATISTICS THROUGH PHILATELY}

\begin{abstract}
This work aims to disseminate some of the content of the history of statistics, in addition to various applications of this science, through images contained in postage stamps issued by several countries between 1843 and 2014. We also present that it is possible to disseminate and teach statistics through philately, highlighting this material being a powerful additional
\end{abstract}

tool in teaching and learning, as well as a scientific element that makes it possible for the society to be aware of the importance of statistics in different areas of knowledge. We also present a description of some stamps of the survey, in addition to a proposal of the use of this rich material in the teaching of statistics, considering it may be applied on related disciplines.

KEYWORDS: Applications in statistics, History of statistics, Statistic learning, Philately. 


\section{INTRODUÇÃO}

Atualmente, a humanidade está cercada por uma grande quantidade de dados e informações que, cada vez mais, exigem diferentes habilidades para fazer a leitura correta e a interpretação dos mesmos. Nesse cenário, torna-se imprescindível saber refletir, compreender, argumentar e agir diante de tantas informações adquiridas ou disponíveis, o que requer muitas vezes a utilização de conteúdos estatísticos.

A mídia em geral tem apresentado cotidianamente exemplos de aplicações envolvendo conteúdos estatísticos relevantes, tais como gráficos, tabelas, índices, dentre outros. Como destaca Silva (2014, p. 26), tomar decisões, na atualidade, "requer conhecimento prévio de informações, fruto de comparações e análises que certamente exigem algum conhecimento estatístico expresso em quaisquer destes formatos a que nos referimos". Entretanto, muitas pessoas se veem perdidas por não terem condições de interpretar e entender o que está por detrás das análises mostradas por essas ferramentas matemáticas. É neste sentido que os Parâmetros Curriculares Nacionais para o Ensino Médio (PCNEM) enfatizam a necessidade de favorecer uma formação ampla aos estudantes, na qual a Estatística ocupa um lugar de destaque (BRASIL, 1997). Não obstante, os PCNEM também apontam para a necessidade da contextualização histórico-social do conhecimento científico, e isso nos remete a estabelecer a importância de se considerar a História da Estatística (HE) nas atividades docentes, pois ela pode contribuir para o aprendizado dos conteúdos estatísticos, visto que permite compreender a origem das ideias que deram forma à nossa cultura. Além dessas considerações, a HE possibilita verificar em que circunstâncias essas ideias ocorreram, mostrando ser um importante instrumento para o ensino nas diferentes áreas da própria Estatística e de outras ciências que a utilizam como ferramenta.

Um ingrediente pouco utilizado para colaborar com o ensino e aprendizagem, que pode ser classificado como "ensino não formal" (Langhi e Nardi, 2009), são os selos postais. Ressalta-se que ao longo da história, coleções temáticas surgiram como uma evolução natural da filatelia e consolidaram-se de forma marcante a partir da metade do século passado. Em princípio, as coleções envolveram o agrupamento de selos isolados de diversos países, retratando um tema ou aspecto específico. Essa modalidade de filatelia acabou revelando uma nova faceta ao selo postal: o seu valor cultural e didático, além de um importante veículo de comunicação dos valores de uma dada sociedade (Castro, Diniz e Barros, 2007; Salcedo, 2010). Em que pese as diferenças entre os vários tipos de coleções, um único ideal une os filatelistas de todo o mundo: a vontade de conhecer mais sobre um local, objeto, pessoa, país, cultura, etc. É exatamente a busca pelo conhecimento que estimula um filatelista a continuar sua coleção, apesar da diminuição das correspondências via o correio tradicional, em função das operações que podem ser realizadas por meio da mídia eletrônica e digital.

Ao longo dos últimos anos diversos artigos científicos empregando os selos postais foram publicados. Normalmente, esses materiais contêm séries magníficas que retratam as mais diferentes áreas do saber. As pesquisas realizadas por Penereiro e Ferreira (2011) e Ferreira, Penereiro e Jacobini (2012) abordam essa temática, sendo que a segunda trata a Estatística empregando os materiais disponíveis da filatelia mundial. Essas pesquisas não são apenas interessantes para o público admirador da filatelia, mas também para aqueles professores que 
atuam nas áreas da Matemática e Estatística e que apreciam a história, as conquistas e as aplicações que esse ramo da Ciência produziu ao longo do tempo.

O uso do material filatélico pode estimular os estudantes a apreciar, entender e analisar as imagens que retratam personagens que contribuíram com desenvolvimento da humanidade, bem como as diversas aplicações da Estatística. Além disso, a filatelia oferece às pessoas, em particular aos estudantes em formação profissional, um estudo mais aprofundado, íntimo, sedutor, instigante, esclarecedor e científico, a respeito de um espaço visual de ordens políticas, culturais e temáticas de vários países, incluindo o Brasil, ao longo desses mais de um século e meio de existência dos selos postais.

Não obstante, como partes da HE e alguns conteúdos dessa ciência estão presentes em vários selos, eles podem ser uma ferramenta didática adicional, propícia para levantar discussões e reflexões das situações que vivenciaram alguns cientistas.

O presente trabalho visou, por meio de pesquisas em catálogos e na Internet, efetuar um levantamento dos selos emitidos em vários países que se relacionam com a $\mathrm{HE}$ e os conteúdos estatísticos. Entende-se que esse tipo de material possa ser explorado pelo professor e seus alunos em várias questões no âmbito dessa ciência, empregando as imagens contidas nos selos e estabelecendo, por exemplo, quais foram os legados deixados por alguns cientistas, as ideias por eles concebidas, além das aplicações em diversas áreas do saber como o emprego de gráficos, histogramas, tabelas, comparações, dentre outras.

Tendo em vista a necessidade de incentivar e ampliar o uso do material filatélico em meios eletrônicos e impressos, este trabalho remete às pessoas interessadas um desafio estimulante - o de aplicar esses materiais filatélicos no ensino e aprendizagem, visando estimular seus alunos não apenas nas abordagens da história e dos conteúdos estatísticos, mas também à prática do colecionismo, como incentivo ao civismo e à educação da ciência.

\section{PROCEDIMENTOS METODOLÓGICOS}

Fez-se uma análise dos selos postais emitidos pela Empresa Brasileira de Correios e Telégrafos (ECT) durante os anos de 1843 a 2014, por meio de um levantamento do material filatélico pertencente à coleção particular de um dos autores. Complementarmente, foram analisados selos emitidos por diversos países usando as facilidades disponíveis na Internet. Adicionado a esses procedimentos, para o caso dos selos brasileiros, fez-se uso do "Catálogo de Selos do Brasil 2013" (Meyer, 2013), por ser a publicação que divulgou todos os selos nacionais lançados desde 1843 até início de 2012.

Diante do levantamento realizado, foram selecionadas diversas estampas emitidas por vários países, incluindo o Brasil, que possuíam alguma relação com a Matemática e Estatística. No total, identificou-se 89 selos envolvendo a temática de interesse (Estatística) durante o período de 1920 a 2014. Desse total, 45 estampas foram selecionadas para atender os objetivos dessa pesquisa, ou seja, restringiu-se a amostra com aqueles selos contendo apenas a conotação Estatística. 
É importante frisar que nem todos os cientistas e os conteúdos das áreas da Estatística foram contemplados nas emissões postais realizadas neste levantamento, o que acarretou inevitáveis lacunas filatélicas neste trabalho.

\section{RESULTADOS}

Para melhor organizar o trabalho optou-se em dividir os resultados encontrados no levantamento em três secções. A primeira refere-se às personalidades da HE, na segunda discorre-se sobre as aplicações da Estatística vislumbradas em algumas estampas e na terceira apresentam-se alguns selos com conotação acadêmica no âmbito da Estatística, como as realizações de congressos, simpósios, clubes, escolas, dentre outros, que contribuíram para o desenvolvimento dessa ciência.

Com o intuito de fornecer subsídios aos interessados, sempre que possível, para cada emissão são tecidos alguns comentários associados às imagens contidas em cada material filatélico exposto.

Posteriormente, discute-se a situação atual em que se encontra a filatelia nacional e são apresentadas propostas para o uso de selos postais pelos docentes.

\subsection{Aspectos históricos da Estatística empregando a filatelia}

Algumas pessoas que dedicaram parte de suas vidas no desenvolvimento de algum ramo da Matemática e Estatística foram homenageadas e aparecem em diferentes séries filatélicas. No levantamento realizado, essa temática (Personalidades) foi representada com 29 selos dos quais se destacam 16 nas Figuras 1 e 2 . A seguir são comentados alguns momentos da HE e, por meio de estampas postais do presente levantamento, são apresentadas algumas imagens das personalidades que contribuíram nesse meio científico.

Acredita-se que o primeiro levantamento estatístico, datado em $3050 \mathrm{AEC}^{1}$, mostrando as riquezas da população do Egito, pode ser atribuído ao historiador grego Heródoto (485-420 AEC), que descreveu aquela atividade como tendo a finalidade de verificar quais eram os recursos humanos e econômicos disponíveis para a construção das famosas pirâmides egípcias (BRASIL, 2009).

Diversos relatos históricos revelam que até o início do século XVII a Estatística seguia uma linha de atuação que pode ser considerada como descritiva. Isso pode ser percebido na Inglaterra, onde os pioneiros trabalhos dos matemáticos ingleses John Graunt (1620-1674) e Sir William Petty (1623-1687) foram direcionados no sentido de usar os registros dos nascimentos e mortes de pessoas para explicar os fenômenos sociais e políticos. Esse tipo de procedimento contribuiu para a denominação da Estatística ${ }^{2}$ como a "Aritmética do Estado".

\footnotetext{
${ }^{1}$ Abreviação de "antes da Era Comum", notação que vem substituir o mais usual a.C. (antes de Cristo), visto que atualmente já se sabe que a data do nascimento de Jesus Cristo foi calculada com equívoco pelos primeiros cronologistas. Quando as datas não forem seguidas pelas letras AEC, significa que elas pertencem à Era Comum.

${ }^{2}$ Imagina-se que a palavra Estatística esteja associada à palavra de origem latina status (estado).
} 
Numa linha de atuação bem diferente, o astrônomo inglês Edmond Halley (1656-1742), fazendo uso dos dados obtidos por Graunt, elaborou a partir de 1693 as primeiras listas ou tabelas baseadas nos registros de mortalidade. A Figura $1 \mathrm{~A}$ reproduz o selo emitido pela República Democrática de Benin em 1986, mostrando Halley ao lado das ilustrações contendo o mais famoso cometa que, por sinal leva seu nome, e a sonda japonesa Giotto, que estudou detalhes daquele astro na sua última passagem por perto do Sol entre 1985 e 1986.

Neste mesmo século, como consequência dos chamados "jogos de azar", surgiram os primeiros estudos sobre o que veria a ser denominado mais tarde de Teoria das Probabilidades, introduzindo um caráter mais científico à Estatística. Blaise Pascal (1623-1662) e Pierre de Fermat (1601-1665) foram os grandes responsáveis por esse desenvolvimento das bases dessa teoria. Os selos da República Francesa, Figuras 1B e 1C, mostram, respectivamente, essas duas personalidades do meio acadêmico/científico. Além deles, o antigo selo francês datado de 1955 e mostrado na Figura 1D revela Pierre Simon Laplace (1749-1827), considerado o fundador da Teoria das Probabilidades por ter trabalhado e publicado importantes textos especialmente no âmbito da distribuição probabilística.

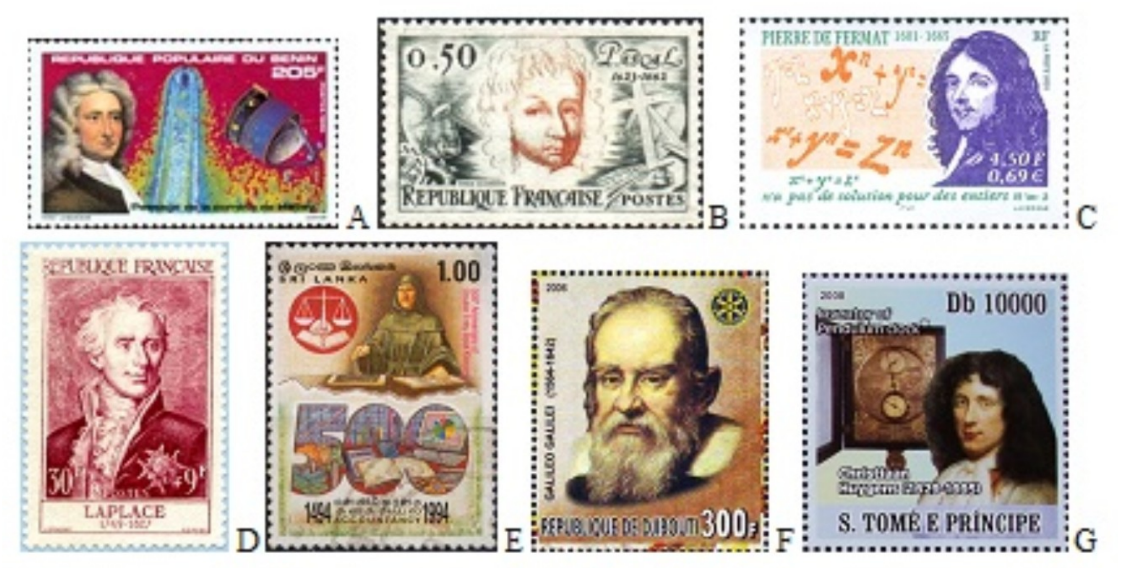

Figura 1: Alguns selos postais emitidos por diferentes países retratando cientistas que se envolveram com a evolução da Estatística entre os séculos XV e XVII.

No entender de Alex Bellos (2011), a Teoria das Probabilidades teve a sua origem na Itália, com especial referência para os matemáticos Luca Bartolomeo de Pacioli (1445-1517), mostrado no selo de Sri Lanka (ou, na forma portuguesa equivalente Ceilão) da Figura 1E; Girolamo Cardano (1501-1576); Niccolò Fontana que também é conhecido por Tartaglia (1499-1557) e o físico Galileo Galilei (1564-1642), ilustrado na estampa de 2006 do pequeno país africano denominado República do Jibuti (Figura 1F). Analisando os trabalhos desenvolvidos por essas personalidades, verifica-se que essa teoria teve como ponto de partida a constatação do vício imoderado das pessoas pelos jogos.

O cientista holandês Christiaan Huygens (1629-1695), retratado juntamente com um dos seus maiores inventos, o relógio de pêndulo, é mostrado no selo das Ilhas San Tomé e Príncipe (Figura 1G). De acordo com Eves (2005), a partir das correspondências firmadas entre Pascal e Fermat, Huygens elaborou, em 1657, o primeiro tratado formal sobre "jogos de azar", sob o título Libellus de Ratiociniis in Ludo Aleae ("O Valor de todas as Chances"). Somente mais tarde é 
que Jakob Bernoulli (1654-1705) aprimorou esse assunto dando um caráter mais científico à teoria probabilística. Bernoulli foi lembrado em 1994 no selo suíço da Figura 2A onde aparece ao lado de um gráfico e da equação para o valor esperado de uma variável.

Não obstante, muitos outros matemáticos europeus se envolveram em estudos específicos da teoria probabilística e contribuíram significativamente para evolução desse ramo da Estatística. Dentre eles destacam-se Gottfried Wilhelm von Leibniz (1646-1716) (Figura 2B); Abraham De Moívre (1667-1754); Daniel Bernoulli (1700-1782), filho de Johann Bernoulli e irmão de Jakob Bernoulli; Leonhard Euler (1707-1783) (Figura 2C); Joseph Louis Lagrange (1736-1813) (Figura 2D) e Henri Poincaré (1854-1912) (Figura 2E). Porém, foi somente a partir do século XIX que a Teoria das Probabilidades teve efetivamente um grande impulso, em particular devido às contribuições do matemático alemão Johann Carl Friedrich Gauss (1777-1855), quando empregou dados astronômicos aos novos métodos de análises por ele propostos e verificou as vantagens destes com relação à significativa qualidade das informações conquistadas.

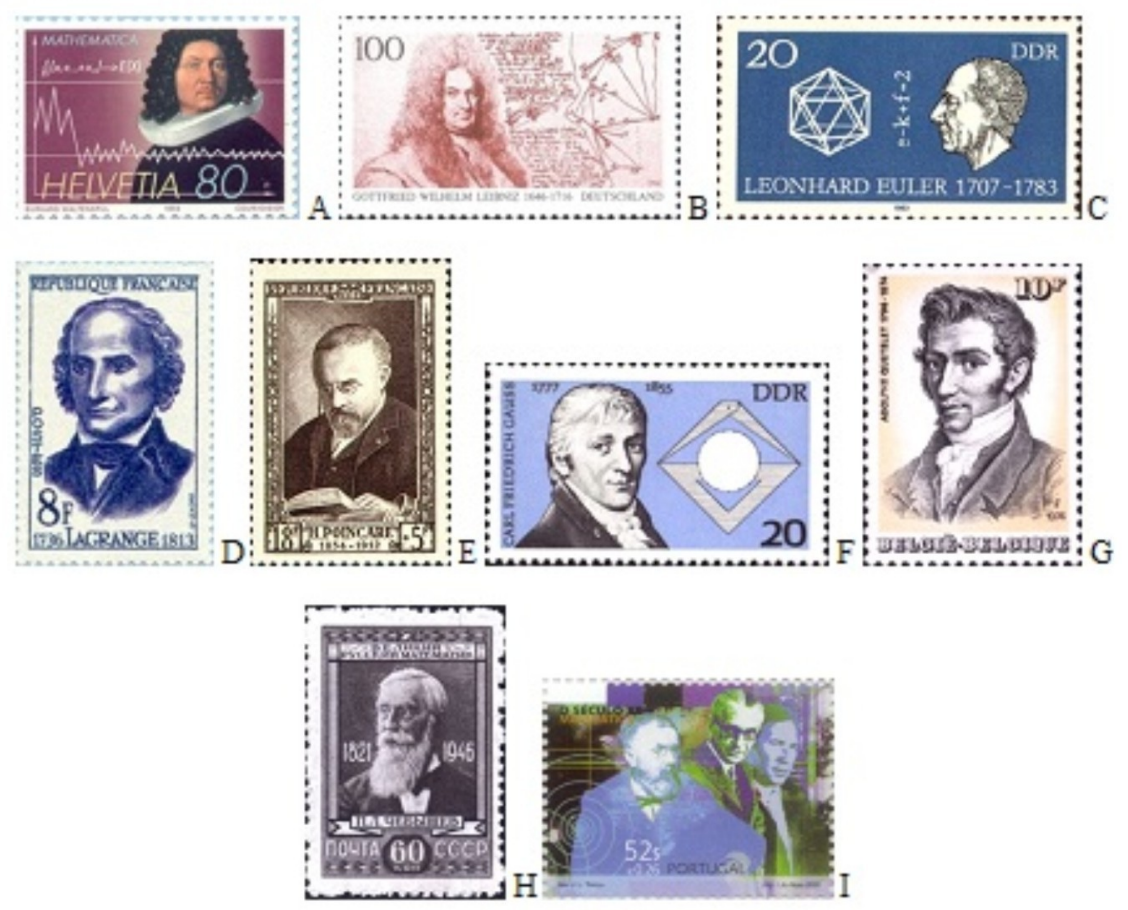

Figura 2: Selos postais que retratando cientistas que desenvolveram parte da Estatística entre os séculos XVII e XX.

Por ter se envolvido nas mais diversas áreas da Matemática, Gauss é atualmente considerado o "Príncipe dos Matemáticos". No âmbito da Estatística, ele é reconhecido pelo desenvolvimento do método dos mínimos quadrados e das leis fundamentais da distribuição das probabilidades. Quando empregou dados astronômicos a esses novos métodos de análises por ele propostos, verificou as vantagens destes com relação à significativa qualidade das informações conquistadas. Gauss foi lembrado no selo emitido pela extinta Alemanha Oriental (Figura 2F), juntamente com um polígono equilátero de 17 lados dentro de um círculo, construído somente com um esquadro e compasso, em alusão a um dos seus feitos científicos. 
Mas, foi somente a partir da metade do século XIX que a Estatística Teórica e Aplicada teve um grande impulso em decorrência das contribuições de eminentes matemáticos e pensadores europeus como: Johann Carl Friedrich Gauss (1777-1855); Siméon Denis Poisson (1781-1840); Lambert Adolphe Jacques Quételet (1796-1874); Antoine Augustin Cournot (18011877); Francis Galton (1822-1911); Karl Carl Pearson (1857-1936); Walter Frank Raphael Weldon (1860-1906); William Sealy Gosset (1876-1936) e Ronald Aylmer Fisher (1890-1962).

Uma importante contribuição da Estatística, sobretudo aplicada aos fenômenos sociais, foi a realizada pelo belga Lambert Quételet quando, pode perceber a existência uma regularidade dos fenômenos sociais ao se levar em consideração a totalidade de uma determinada população. O selo emitido em 1974, e reproduzido na Figura 2G, é uma homenagem de seu país a Quételet.

Os trabalhos do britânico Francis Galton também se destacam pelas aplicações da Estatística nas questões sociais, em particular ao introduzir o uso de questionários e pesquisas para coletar dados sobre comunidades humanas. Foi ele quem definiu pela primeira vez um índice matemático para descrever a consistência da relação entre as alturas de pais e filhos, o que atualmente veio a ser denominado de coeficiente de correlação, isto é, uma fórmula para se medir a regressão à média, daí a letra " $r$ " para designá-la. A fórmula da correlação proposta por Galton foi modificada por Walter Welton e, na forma mais atual, foi estabelecida por Karl Pearson em 1896.

O matemático e filosofo francês Antoine Cournot também realizou importantes investidas à Teoria das Probabilidades. Ele foi o pioneiro no tratamento matemático dado aos fenômenos econômicos que já vinham sendo sentidos por vários países, como inflação, juros, ganhos e perdas de capitais, dentre outros.

Num ambiente bastante diferenciado do acadêmico, onde havia a necessidade de manipular dados provenientes de pequenas amostras extraídas para a melhoria da qualidade das cervejas produzidas pela companhia irlandesa Guiness, é que se destaca a participação do químico William Gosset na Estatística. Foi neste clima industrial que ele conseguiu desenvolver o então denominado "teste $t$ ".

Outro ícone nessa área da Estatística foi o inglês geneticista Sir Ronald A. Fisher. Considerado um dos maiores estatísticos do século XX, ele deu continuidade aos trabalhos desenvolvidos por Gosset, porém adotando uma abordagem mais teórica, introduzindo conceitos inovadores como os de "aleatorização" e da "análise de variância". Fisher é considerado a personalidade mais representativa da denominada Fase da Experimentação da Estatística, pois é tido como o criador dos métodos modernos da análise e delineamento pautados na experimentação voltada à agricultura.

Foi apenas nas duas últimas décadas do século XIX e avançando no século XX que a "Teoria das Probabilidades" atingiu o ápice de seu desenvolvimento, devido colaborações de vários matemáticos russos, dentre eles destacam-se Pafnuty Lvovich Chebyshev (1821-1894), Andrei Andreyevich Markov (1856-1922) e Aleksandr Mikhailovich Lyapunov (1857-1918). O selo soviético de 1946, reproduzido na Figura 2H, é uma homenagem a Chebyshev pelos 125 anos de seu nascimento. Contudo, o maior expoente dessa escola russa foi Andrey Nikolayevich Kolmogorov (1903-1987), pois foi capaz de identificar um conjunto de axiomas para construir toda a teoria probabilística que se usa atualmente. O selo português emitido em 2000 (Figura 2l) 
mostra Kolmogorov juntamente com dois expoentes da matemática do início do século XX, o francês Henri Poincaré e o austríaco, naturalizado americano, Kurt Friedrich Gödel (1906-1978), ambos à direita de Kolmogorov.

Nesta mesma época, os alemães Friedrich Robert Helmert (1843-1917) e Wilhelm Lexis (1837-1914), além do dinamarquês Thorvald Nicolai Thiele (1838-1910) e do inglês Francis Ysidro Edgeworth (1845-1926), obtiveram resultados expressivos para que pudesse ser desenvolvida a Inferência Estatística, muitos dos quais só foram completamente compreendidos e aplicados mais tarde pela própria comunidade científica.

Destacam-se ainda os estatísticos Jerzy Neyman (1894-1981) e o filho de Pearson, Egon Sharpe Pearson (1895-1980), que colaboraram decisivamente para a teoria clássica do "Teste de Hipótese". Neyman, assim como Fisher, também teve a oportunidade de trabalhar em pesquisas voltadas à agricultura, de forma que ambos "disputaram" a primazia de ocuparem lugares de destaques na estatística experimental moderna.

Finalizando este retrospecto histórico, porém limitado, não se deve passar em branco a importante contribuição, realizada já na metade do século $X X$, pelo estadunidense John Wilder Tukey (1915-2000) quando conseguiu relacionar, dentre outros tópicos, as séries temporais aplicadas em modelos lineares, realizar generalizações de alguns trabalhos de Fisher, e aplicar análise exploratória em séries de dados.

\subsection{Algumas aplicações estatísticas contidas nos selos postais}

Tendo em vista a crescente abordagem quantitativa, a Estatística está cada vez mais presente em diversas áreas do conhecimento, isto é, nas Ciências Exatas, Humanas e da Vida. O envolvimento da Estatística com essas áreas pode se dar por meio da Estatística Descritiva ou da Estatística Inferencial.

No âmbito da Estatística Descritiva, podem-se empregar métodos para realizar recenseamentos visando à contagem de indivíduos, propriedades, produtividade, além de informações adicionais relacionadas à família, como saúde, propriedades de bens, grau de instrução, dentre outros. Normalmente, essas informações são apresentadas no formato de tabelas e gráficos. Entretanto, quando as informações coletadas necessitam ser obtidas por amostras que requerem análises mais generalizadas, empregam-se os métodos provenientes da Estatística Inferencial.

Assim são os casos nos quais as investigações médicas necessitam de modelos matemáticos para avaliar distribuições e, assim, determinar os possíveis efeitos de tratamentos específicos em pacientes. Não obstante, os sociólogos e economistas invariavelmente empregam distribuições matemáticas para avaliar o comportamento da sociedade moderna, buscando suas causas e procurando por possíveis soluções. No âmbito da mecânica quântica, os físicos utilizam as distribuições matemáticas para descrever os comportamentos das partículas subatômicas em diferentes situações, visando aplicações para o bem-estar da humanidade.

A seguir, são destacadas algumas estampas postais encontradas no levantamento que se relacionam às aplicações em Estatística. 


\subsubsection{Engenharias e outras áreas afins}

Atualmente, muitos problemas de áreas das Engenharias requerem o entendimento de como usar os conteúdos estatísticos para lidar com, por exemplo, a variabilidade de um produto ou material e seu impacto na tomada de decisão. O "julgamento estatístico" e o "método estatístico" a ser empregado desempenham um papel importante no planejamento, na condução e na análise de dados a partir de experimentos em laboratório. Neste contexto, o uso de "gráficos de controle" é uma ferramenta fundamental apoiada pela Estatística, pois permite monitorar, controlar e melhorar um processo a ser desenvolvido em série, ou ainda, um produto que deva ser testado até a exaustão para inferir, por exemplo, a sua durabilidade. Esse ramo da Estatística é denominado "Controle Estatístico de Processo", ou, simplesmente, CEP.

As áreas da Contabilidade, Finanças, Marketing, Produção e Economia, também se beneficiam com a Estatística, principalmente nas análises envolvendo diferentes testes estatísticos. É o caso da Contabilidade, onde muitas firmas usam procedimentos de amostragem estatística ao realizarem auditorias para seus clientes. Consultores em Finanças também utilizam uma série de conceitos estatísticos para guiar suas recomendações de investimentos. No âmbito do Marketing são empregados conceitos estatísticos em atividade promocionais visando estabelecer futuras estratégias para lançamento de vários produtos. Na Produção o controle de qualidade é uma importante ferramenta da Estatística que, qualquer fábrica que produz bens em escala, se utiliza. Na Economia é possível citar, dentre outras possibilidades, o emprego de informações estatísticas visando possíveis previsões voltadas ao mercado futuro de capitais.

A Figura 3 reproduz exemplos de aplicações da Estatística nas ciências supras citadas por meio de algumas estampas postais que retratam levantamentos estatísticos efetuados em alguns países. É o caso dos selos lançados por Portugal, reproduzidos nas Figuras 3A, 3B e 3C, que mostram a produtividade registrada por aquele país em 1976, na forma de códigos de barras, por meio de dígitos e por gráficos de comportamentos, respectivamente.

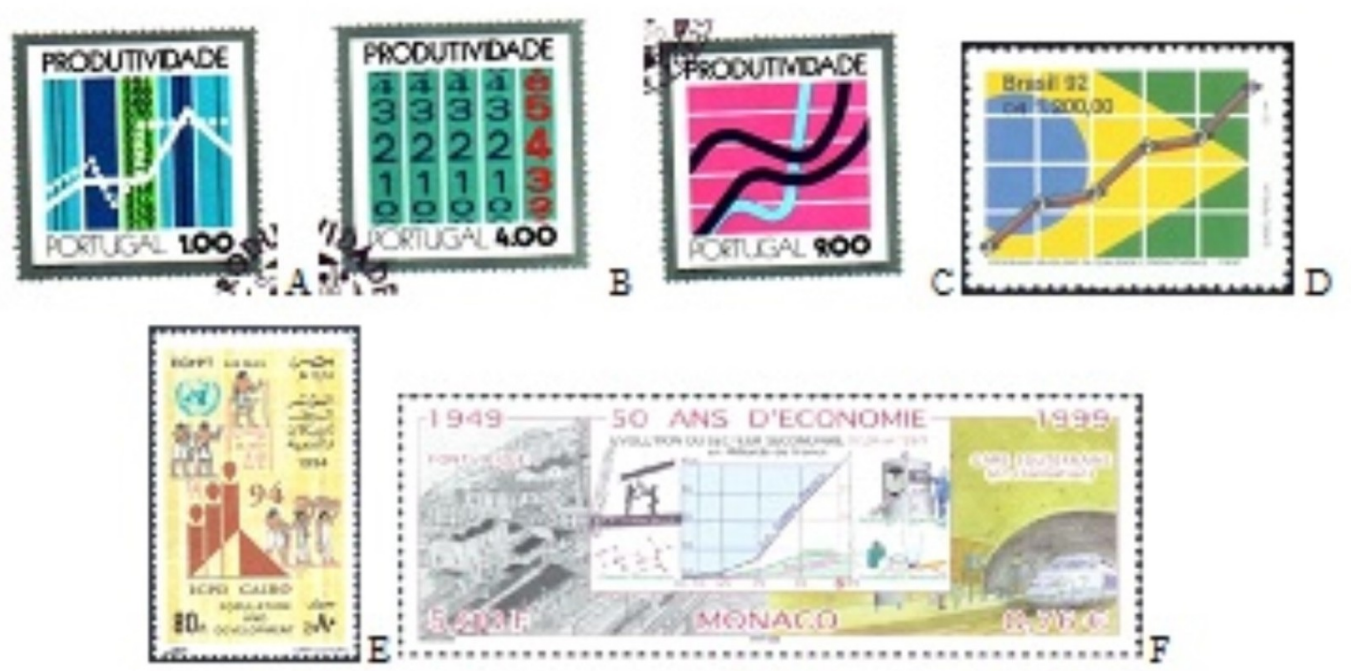

Figura 3: A produtividade econômica de alguns países divulgada por meio dos selos postais. 
Em 1992 a ECT emitiu uma estampa, reproduzida na Figura 3D, em alusão ao Programa Brasil Qualidade e Produtividade. Nela destaca-se um gráfico relativo ao avanço da produção nacional, estando ao fundo parte da bandeira nacional, além da unidade monetária vigente na época, o cruzeiro ( $\mathrm{Cr} \$$ ).

O selo emitido pela República Árabe do Egito, reproduzido na Figura 3E, evidencia a relação entre o aumento da população e o desenvolvimento daquele país, destacando em formato estilizado as famosas Pirâmides do Egito.

O cinquentenário de Economia foi o tema do selo emitido pelo Principado de Mônaco, reproduzido na Figura 3F. Nessa emissão é mostrada a evolução de diversos serviços que atingem a sociedade daquele país, tais como transportes, construção civil, telecomunicações, comércio, dentre outros.

\subsubsection{As contribuições da Física e Química}

No decorrer do pensamento humano, percebe-se que a Estatística, assim como outras ciências, sofreu influência de outras áreas do conhecimento, em particular no âmbito da Física e da Química. Dentre esses, destaca-se inicialmente o britânico James Clerk Maxwell (1831-1897) que, a partir de seus minuciosos estudos sobre a teoria cinética dos gases, pode descobrir uma distribuição de probabilidade para explicar algumas implicações experimentais em Física e Química, como as propriedades nas velocidades e energias das partículas de um gás ideal. Esses estudos também possibilitaram explicar, se bem que parcialmente, o denominado movimento browniano, isto é, o movimento aleatório e imprevisível de alguns sistemas físico-químico, como os líquidos e gases. Um aprimoramento nesses estudos foi realizado posteriormente pelo austríaco Ludwig Boltzmann (1844-1906) que, acabou por desenvolver o que atualmente denomina-se em Física de termodinâmica estatística. Neste contexto, as distribuições de energias ou de velocidades são conhecidas e descritas como uma curva da distribuição estatística de Maxwell-Boltzmann. Maxwell foi homenageado em 1991 com o selo emitido por San Marino que está reproduzido na Figura 4A, enquanto que Boltzmann aparece retratado no selo austríaco de 1951 da Figura 4B. É interessante comentar que os trabalhos realizados por Quételet ajudaram a desencadear os vários estudos desenvolvidos por Maxwell e Boltzmann, que empregaram os novos métodos então vigentes.

Mais tarde os estudos teóricos dos gases foram expandidos para um ramo da Física denominado mecânica estatística. Neste aspecto se destacou o estadunidense Josian Willard Gibbs (1839-1903), em especial na série de artigos com o título geral sobre equilíbrio de substâncias heterogêneas, onde um dos princípios discutidos inclui a regra das fases de Gibbs. 0 selo americano de 2005, reproduzido na Figura 4C, mostra Gibbs e os movimentos aleatórios produzidos pelas partículas de um sistema termodinâmico. 


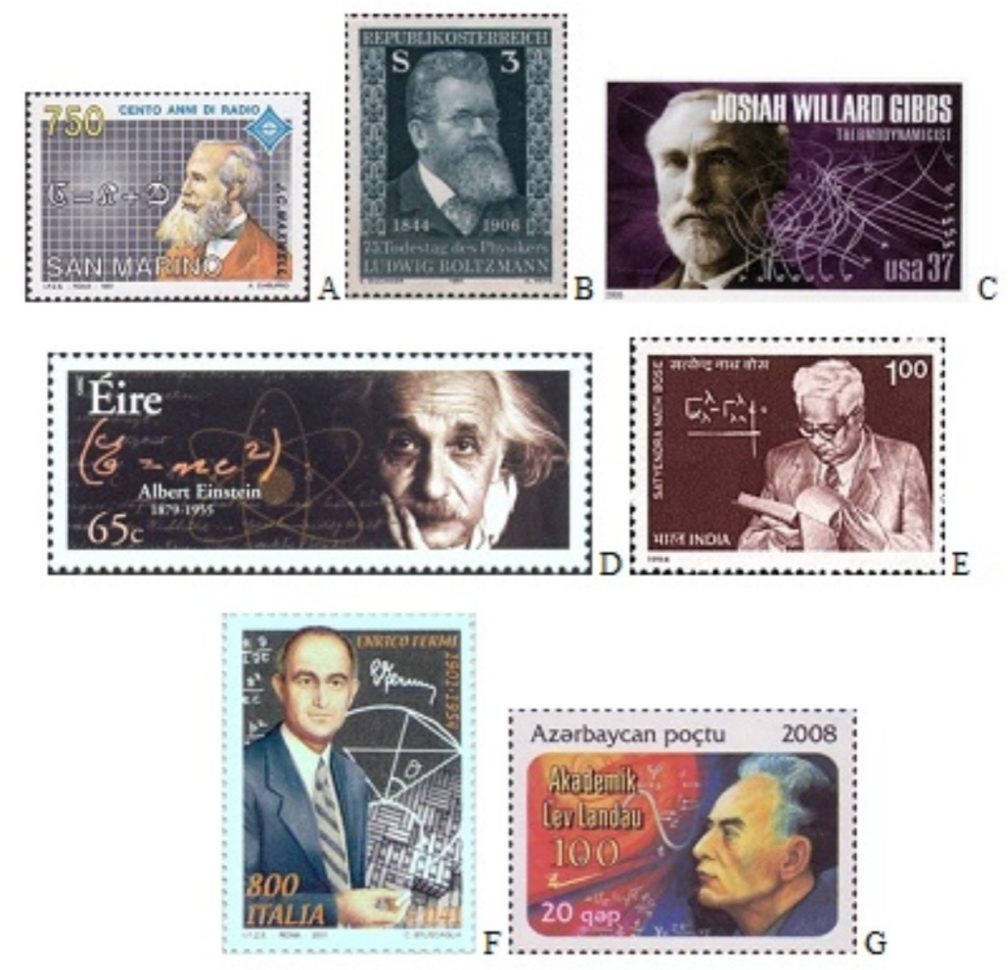

Figura 4: Selos que retratam alguns cientistas que usaram e desenvolveram a Estatística nos últimos anos.

Entretanto, alguns cientistas tinham objeções matemáticas à teoria cinética dos gases, enquanto que outros a rejeitavam totalmente porque, na época, ninguém havia visto ou detectado um átomo isoladamente. Só mais tarde, em 1905, é que o alemão Albert Einstein (1889-1955) complementou a teoria e aplicou-a de forma exata para explicar, com grande detalhamento numérico, o mecanismo preciso do movimento browniano para o comportamento dos átomos e moléculas (Mlodinow, 2008). Einstein, considerado por muitos como o cientista mais famoso do século XX, aparece no selo irlandês reproduzido na Figura 4D com aquela que talvez seja a mais conhecida das equações modernas: $E=m c^{2}$.

A Figura 4E mostra o físico indiano Satyendra Nath Bose (1894-1974) que, em 1920, ficou conhecido pelas suas tarefas desenvolvidas em mecânica quântica, dando sequência aos trabalhos iniciados por Einstein.

No âmbito da mesma mecânica quântica e da física de partículas destaca-se a dedicação e os avanços introduzidos pelo italiano Enrico Fermi (1901-1954) que foi retratado no selo italiano emitido em 2005 (Figura 4F).

O físico e matemático soviético Lev Davidovich Landau (1908-1968) foi lembrado por meio de uma estampa de 2008 emitida pela República do Azerbaijão, reproduzida na Figura 4G, devido as importantes atuações que realizou com os trabalhos voltados à teoria da supercondutividade e a superfluidez, a eletrodinâmica quântica, a física nuclear e a física de partículas, as quais o emprego direto de conteúdos estatísticos é imprescindível. 


\subsubsection{Diferentes censos nacionais e internacionais}

Como salientado no início deste trabalho, a Estatística surgiu como uma necessidade do Estado, visando, principalmente, a cobrança de impostos e aplicar os recursos arrecadados, mesmo que parcialmente, em benefício da população. Neste sentido, ao longo do tempo, vários países vêm empregando a Estatística para realizar vários estudos e, sempre que possível, realizar previsões em algum setor, econômico, social, ou político, de interesse.

No Brasil não é diferente, pois desde a década de 1940 a filatelia brasileira demonstra a preocupação do governo em realizar estudos estatísticos em benefício da população. É o caso do primeiro selo, reproduzido na Figura 5A, relacionado à convocação ao 5o Recenseamento Geral do Brasil, ocorrido num dia de domingo em 01/09/1940. O selo da Figura 5B é em alusão ao quinquagésimo aniversário do Instituto Geográfico e Histórico da Bahia, órgão também destinado a elaborar censos e cadastramentos de informações físicas e jurídicas.

O recenseamento de 1950 foi lembrado com o selo mostrado na Figura $5 C$, no qual aparecem os dizeres: "AJUDE A VERIFICAR A GRANDEZA DO BRASIL". Em pleno regime militar, o VII Recenseamento Geral do Brasil, ocorrido em 1970, foi o tema da estampa nas cores verde e amarelo, mostrada na Figura 5D.
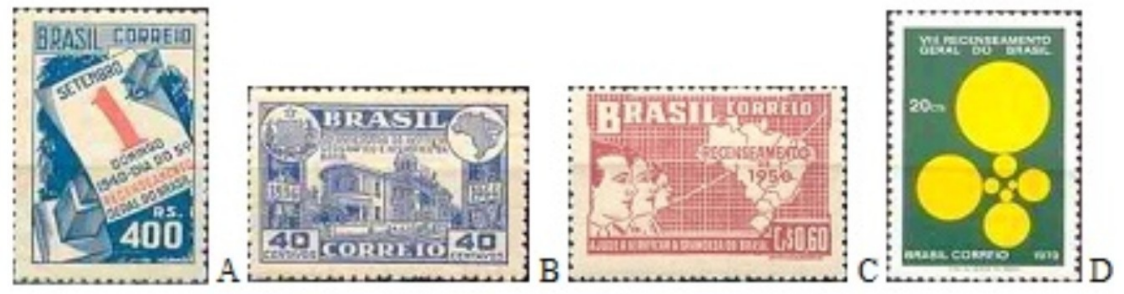

Figura 5: Selos postais brasileiros cuja temática aborda os diferentes recenseamentos.

Outros países também deram atenção aos censos populacionais. É o caso da República Árabe do Egito que emitiu o selo mostrado na Figura 6A retratando o censo escolar ocorrido em 1975. O Reino da Noruega, em 1976, lançou o selo em alusão ao centenário Central de Estatística daquele país destacando o comportamento populacional e o desenvolvimento nos transportes e na qualidade das moradias (Figura 6B).
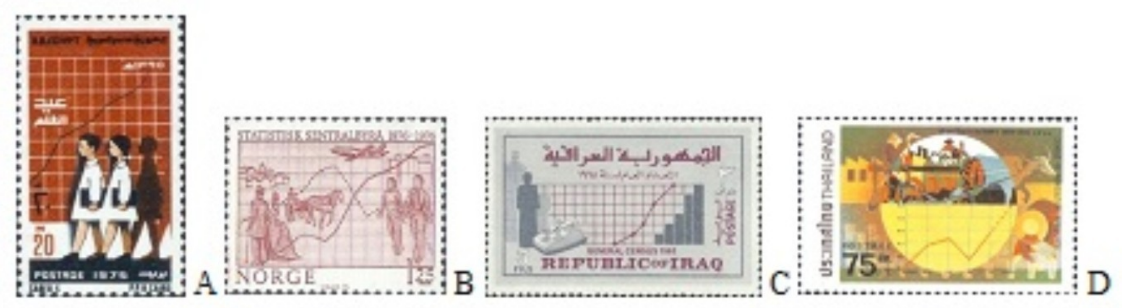

Figura 6: Selos de alguns países que abordam o tema recenseamento em vários contextos.

O censo geral ocorrido em 1965 na República do Iraque foi o tema do selo reproduzido na Figura 6C. A Figura 6D reproduz o selo em alusão ao Censo Agrícola ocorrido em 1978 no Reino da Tailândia. 
É interessante ressaltar que na maior parte das estampas ilustradas nas Figuras 3, 4 e 5 foram inseridos gráficos e histogramas de curvas estatísticas lembrando o crescimento populacional, econômico, educacional, entre outros, de uma determinada nação, retratando com isso a importância dessa ciência para a sociedade.

\subsection{Conotações acadêmicas}

O primeiro Congresso Internacional de Matemática ocorreu em 1893 na cidade americana de Chicago. A partir de então, muitos outros encontros científicos foram promovidos em diferentes países envolvendo não só temas da Matemática, mas invariavelmente discutindo-se questões do âmbito da Estatística, seja em termos de suas técnicas e aplicações, ou em conclaves para discutir formas de ensino e aprendizagem. Diante do levantamento realizado neste trabalho, optou-se por destacar apenas alguns selos postais que retrataram congressos nacionais e internacionais, estando reproduzidos na Figura 6.

As duas primeiras ilustrações da Figura 7 mostram os selos brasileiros dedicados ao Instituto Nacional de Matemática Pura e Aplicada (IMPA). O selo da Figura 7A, lançado em 21/07/1967, é em alusão do 60 Colóquio Brasileiro de Matemática promovido pelo IMPA, ocorrido entre 2 e 22 de julho de 1967 em Poços de Caldas, MG (IMPA, 2013). Na estampa postal relacionada à "Promoção das Ciências", emitida em 11/07/1974, aparece outra homenagem ao IMPA (Figura 7B). Observa-se nesses dois selos o logotipo do IMPA, representado pela denominada "banda de Möbius", ou, como também é conhecida, "fita de Möbius". Apenas como curiosidade, seguindo a borda da fita com um dedo, constata-se que se atinge o ponto de partida tendo percorrido "ambas as bordas", portanto, verifica-se que só existe uma única borda nessa superfície (Möbius, 2015).

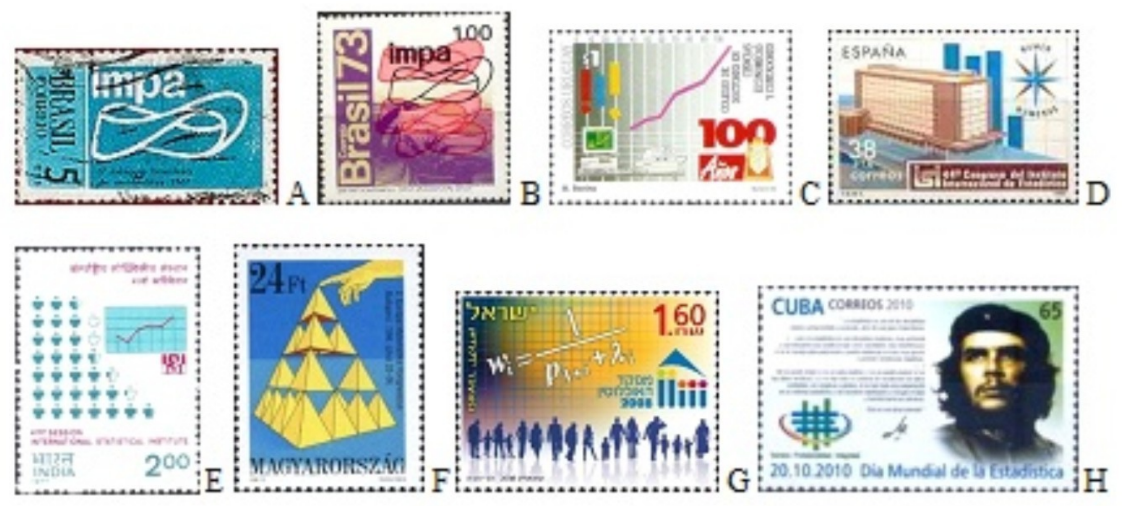

Figura 7: Alguns selos postais emitidos por diferentes países, inclusive o Brasil, em alusão as ocorrências de Encontros Científicos Nacionais e Internacionais em Matemática e Estatística.

Na figura também está ilustrado o selo uruguaio de 1993, reproduzido na Figura 7C, destacando o centenário do Colégio de Doutores em Ciências Econômicas e Contadores, existente naquele país. O 44을 Congresso do Instituto Internacional de Estatística, ocorrido na cidade espanhola de Madrid, foi o tema do selo espanhol emitido em 1983. Neste selo, reproduzido na Figura 7D, é possível perceber ao fundo do prédio ilustrado, onde se desenvolveu 
o referido evento, um histograma de barras enaltecendo a Ciência Estatística.

O selo da Figura 7E, emitido em 1977 pela República da Índia, em homenagem a 41a Sessão Internacional do Instituto de Estatística, revela um pictograma enfatizando o preocupante crescimento populacional daquele país. A Figura 7F mostra o selo do 20 Congresso Europeu de Matemática ocorrido, em 1996, na República da Hungria. Um selo, em homenagem ao Escritório Central de Estatística, emitido por Israel em 2008, está reproduzido na Figura 7G. Por fim, o selo da Figura 7H emitido em 2010 pela República de Cuba ilustra o Dia Mundial de Estatística, comemorado na data de 20 de outubro de cada ano e apresenta um texto de Ernesto Rafael Guevara de la Serna (1928-1967), conhecido como "Che Guevara", um dos ideólogos e comandantes que lideraram a revolução cubana.

Constata-se que, também nestas estampas postais, frequentemente foram usados números, gráficos, histogramas e figuras atraentes para chamar a atenção de eventuais participantes aos eventos, assim como dos colecionadores filatélicos.

\subsection{A situação filatélica atual e propostas de ações em atividades docentes}

Apesar da ciência Estatística ser um tema timidamente explorado por filatelistas espalhados pelo mundo, ela não passou despercebida no Brasil pela ECT. Certamente, nos países da Comunidade Europeia e nos Estados Unidos encontra-se uma maior tradição e cuidado na apresentação dos temas filatélicos. A título da importância que esses povos dão à filatelia, destacam-se os livros: "Um Certo Olhar pela Filatelia", do português Luis Eugénio Ferreira (Ferreira, 2006), e "European Stamp Design: a semiotic approach to designing messages", do irlandês David Scott (Scott, 1995). Na primeira obra o autor ressalta a importância dos selos por meio de aspectos da política e história dos povos europeus. A segunda aborda de forma pioneira o selo postal sob uma perspectiva da semiótica. Neste livro os elementos icônicos e simbólicos são abordados sob o olhar dos selos postais, explorando o design filatélico de cinco países (França, Holanda, Inglaterra, Irlanda e Suíça). Numa passagem da referida obra, Scott dimensiona a importância do selo nas seguintes palavras: "o selo postal adesivo possui uma densidade de concentração ideológica por polegada quadrada maior do que qualquer outra forma de cultura humana" (Scott, 1995).

O Brasil também não deixou passar em branco a importância que a filatelia proporciona, tanto no sentido de ser um eficaz meio de comunicação e informação de massa, como uma ferramenta adicional para popularizar conhecimentos de diferentes áreas do saber. Neste contexto, a obra intitulada "A ciência nos selos postais comemorativos brasileiros: 1900-2000" de Diego Andres Salcedo, instiga o leitor a utilizar o selo postal como instrumento pedagógico, permitindo mediar realidades, assim como fazem outros media (fotografia, cinema, novela, romances dentre outros) (Salcedo, 2010).

É importante ressaltar que para um colecionador, uma simples paisagem exibindo uma árvore, uma praia, um pássaro, ou o busto de um personagem da história, pode ser explorada de algum ponto de vista da Ciência. Entretanto, é necessário diferenciar os selos nos quais o motivo temático apenas faz parte da "paisagem de fundo" daqueles em que esse tema é o principal motivo estampado. Justamente, nesse último grupo são encontrados alguns dos selos mais belos de divulgação e úteis para o uso dos professores com seus estudantes em atividades acadêmicas. 
Neste contexto, os selos postais podem servir como mais uma opção para o ensino e para a aprendizagem, pois esse material é um recurso diferente podendo fazer uso de dispositivos auxiliares como retroprojetores, datashow, fotografias, internet, dentre outros.

Com certeza, a abordagem educativa ainda é um desafio para muitos educadores, indicando que há um longo caminho a ser percorrido. Mas, vale destacar que, a aprendizagem das ciências, e por que não dos conteúdos científicos, pode acontecer em âmbitos diversificados, como no caso da educação formal, informal, ou ainda nas atividades denominadas de popularização da ciência. Assim, quanto mais ampla a divulgação, a disseminação e a difusão dos conteúdos existentes nos selos postais, mais facilmente e com maior eficiência ocorrerá a transposição didática de saberes científicos.

Desde que tais espaços não formais, como os que foram aqui propostos por meio do uso dos selos postais, sejam utilizados com a finalidade de participar dos processos de ensino e aprendizagem de forma planejada, sistemática e articulada, o material filatélico empregado deixa de se tornar uma mera atividade educacional de complementação ou de lazer, passando a contribuir para a educação e o aprendizado de conteúdo geral ou, em certas aplicações, específico de um curso de ciências.

Além de mostrar a existência de vários selos postais com conotação acadêmica, em particular na Estatística, a presente pesquisa tem como intuito sugerir o uso pedagógico da filatelia, tendo em vista que as estampas postais representam um rico material de divulgação do conteúdo histórico de várias ciências, possibilitando assim o desenvolvimento, na sala de aula, de temas culturais, econômicos e sociais.

No caso de atividades envolvendo a HE por meio do material aqui apresentado, o diagrama da Figura 8 ilustra uma sugestão para o seu uso na prática docente. Este diagrama tem como objetivo mostrar que professores e estudantes podem utilizar a Estatística retratada nos selos postais e, paralelamente, fazer a interseção com a HE e as aplicações que essa ciência promoveu para a sociedade, revelando os aspectos culturais, econômicos, históricos, geográficos e sociais. Os aspectos visuais contidos nas estampas postais podem despertar a curiosidade e o interesse do estudante e, como consequência, ampliar o seu conhecimento. Por meio desse material filatélico é possível instigar o estudante a descobrir a origem de um determinado conteúdo estatístico, tornando a aprendizagem não apenas significativa, mas, igualmente, motivadora. Além disso, as estampas postais podem proporcionar alguns questionamentos e discussões sobre a evolução da Estatística presente nas imagens e relacioná-la com outras áreas do conhecimento, podendo favorecer a criticidade a respeito das informações retratadas nessas estampas postais. Por ser um material didático não convencional e de fácil manuseio, é possível utilizá-lo como uma opção adicional para o ensino e para aprendizagem e, por conseguinte, auxiliar os professores que desejarem estimular os seus estudantes a apreciar, analisar e estudar as imagens retratando personalidades da HE. 


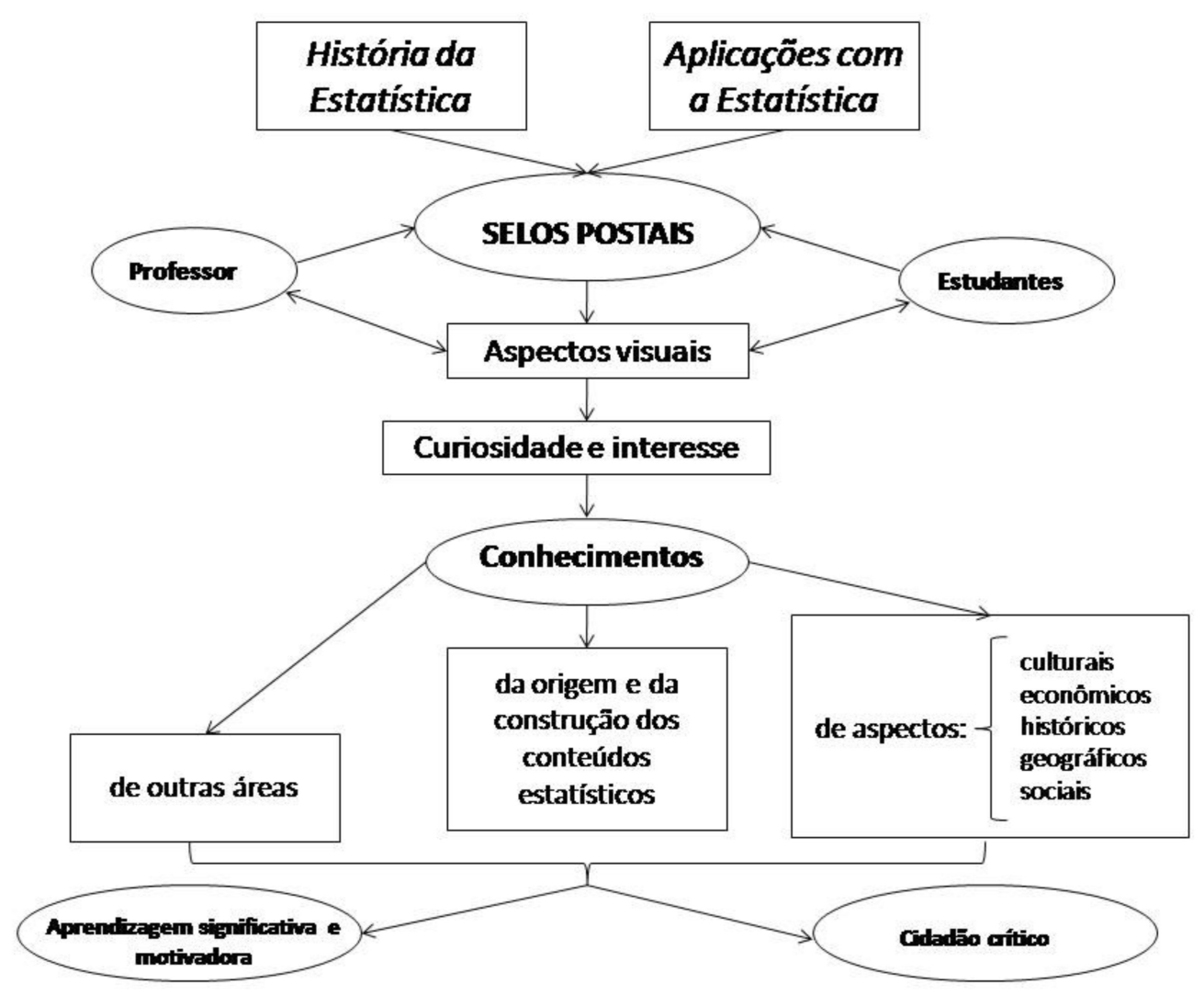

Figura 8: Diagrama básico de uma abordagem didática envolvendo o uso de selos postais.

Embora a amostra aqui apresentada seja reduzida, é possível observar a riqueza de detalhes existentes nesse pequeno fragmento de papel - o selo postal comemorativo. Dessa maneira, o seu uso torna-se viável no processo de ensino e aprendizagem, de forma planejada, sistemática e articulada, não apenas como uma atividade educacional de complementação.

\section{CONSIDERAÇÕES FINAIS}

O levantamento filatélico realizado revelou que o Brasil emitiu 4435 selos entre 1843 e 2014. Deste material, constatou-se que sete estampas (Figuras 2D, 3A, 3B, 3C, 3D, 5A e 5B) possuem envolvimento em conteúdos estatísticos, o que indica a importância desse tipo de material para uso didático. Com relação aos selos emitidos por outros países, verificou-se a existência de 89 emissões com temas relacionados à Estatística no período de 1920 a 2014. Devido ao grande número de estampas filatélicas neste tema, pode-se concluir que a filatelia mundial vem cumprindo um dos seus papéis sociais mais relevantes, o da divulgação da Ciência a serviço da humanidade.

Defende-se que esse tipo de material possa ser utilizado por um professor como mais um recurso didático. É o tipo de material que pode ser empregado com alunos em discussões que abordam a evolução da HE ao longo do desenvolvimento da humanidade, assim como suas aplicações e possíveis implicações para a sociedade contemporânea. 
Ressalta-se que, dentre as diferentes mídias disponíveis, os selos postais ainda representam um poderoso veículo de comunicação ainda pouco utilizado pelos professores em sala de aula ou em trabalhos extraclasse. O conteúdo existente nas imagens impressas nas estampas, muitas vezes possibilita realizar uma abordagem diferente e motivadora das análises de conteúdos históricos, retratando a evolução da estatística ao longo dos tempos e seus vínculos e utilizações no âmbito das outras ciências, como é o caso da Geografia, Física, Química e a própria Matemática.

Finalmente, pode-se concluir, por meio deste trabalho, que a Estatística vem sendo divulgada por meio da filatelia, caracterizando nas emissões de vários selos postais de diferentes países alguns elementos da história e da evolução das aplicações desta ciência.

\section{REFERÊNCIAS}

Bellos, A. (2011). Alex no país dos números: uma viagem ao mundo maravilhoso da matemática. Tradução de Berilo Vargas e Claudio Carina. São Paulo: Editora Schwarcz Ltda, 490p.

BRASIL (1997). Parâmetros Curriculares Nacionais para o Ensino Médio: Matemática. Secretaria de Educação Média e Tecnológica. - Brasília: MEC/SEMTEC, 92p. Versão preliminar. $\begin{array}{lllll}\text { Recuperado em } & 17 & \text { dezembro, } & 2017 & \text { de }\end{array}$ http://portal.mec.gov.br/seb/arquivos/pdf/livro03.pdf.

BRASIL (2009). Ministério da Educação. Secretaria de Educação Básica. Medeiros, C. A. Estatística aplicada à Educação. Brasília: Universidade de Brasília, 134p. Recuperado em 10 dezembro, 2017 de http://portal.mec.gov.br/index.php?option=com_content\&view=article\&id=13155.

Castro, J.F.M.; Diniz, A.M.A. \& Barros, G.F. (2007). Interseções Geográficas: uma análise da cartografia filatélica brasileira. Sociedade \& Natureza, 19(2), 153-169.

Eves, H. (2005). Introdução à História da Matemática. Campinas: Editora UNICAMP.

Ferreira, L.E. (2006). Um Certo Olhar pela Filatelia. Santarém (Portugal): Edições Húmus, 125p.

Ferreira, D.H.L.; Penereiro, J.C. \& Jacobini, O.R. (2012). Retratando a evolução da Estatística por meio de imagens contidas em selos postais comemorativos. Revista Brasileira de História da Matemática, 12(5), 31-49.

IMPA (2013). - Instituto Nacional de Matemática Pura e Aplicada. Colóquio Brasileiro de Matemática. Recuperado em 11 janeiro, 2013 de http://www.impa.br/opencms/pt/pesquisa_coloquio_brasileiro_de_matematica/índex.html.

Langhi, R.; Nardi, R. (2009). Ensino da astronomia no Brasil: educação formal, informal, não formal e divulgação científica. Revista Brasileira de Ensino de Física, 31(4), p. (4402) - 1-11,

Meyer, P. (2013). O Catálogo de Selos do Brasil 2013. 58aed. São Paulo: Editora RHM Ltda, 608p.

Mlodinow, L. (2008). O andar do bêbado: como o acaso determina nossas vidas. Tradução de Diego Alfaro. Rio de Janeiro: Editora: Zahar, 261p.

Penereiro, J.C. \& Ferreira, D.H.L. (2011). Filatelia como mecanismo de divulgação e de ensino para as Engenharias do Brasil. RBECT - Revista Brasileira de Ensino de Ciência e Tecnologia, $4(2), 84-104$. 
Möbius, A.F. (2015). Banda de Möbius. Recuperado em 05 janeiro, 2015 de http://pt.encydia.com/es/Banda_de_Möbius.

Salcedo, D.A. (2010). A ciência nos selos postais comemorativos brasileiros: 1900-2000. Recife: Editora Universitária - UFPE, 216p.

Silva, J.F. (2014). O uso das TICs no ensino superior e suas contribuições para a educação estatística. 115 f. Dissertação (Mestrado em Ensino de Ciências) - Universidade Cruzeiro do Sul, São Paulo.

Scott, D. (1995). European Stamp Design: a semiotic approach to designing messages. Londres: Academy Editions, 143p. 